\title{
HISTÓRIAS DAS DIFERENÇAS E DAS DESIGUALDADES REVISITADAS: NOTAS SOBRE GÊNERO, ESCRAVIDÃO, RAÇA E PÓS-EMANCIPAÇÃO
}

\author{
MARCELO PAIXÃO
}

Universidade Federal do Rio de Janeiro

FLÁVIO GOMES

Universidade Federal do Rio de Janeiro

Resumo: Este artigo procura refletir sobre aspectos da história da escravidão, da pósemancipação e do tempo presente da mulher negra, especialmente em termos de sua atual inserção no mercado de trabalho. Na primeira parte, o artigo aborda a bibliografia sobre a história da mulher escrava e analisa algumas narrativas sobre famílias, cotidiano e estratégias femininas de escravas, crioulas, forras e africanas nos séculos XVIII e XIX a partir de testamentos. Na segunda parte, o artigo busca estabelecer um diálogo entre os tempos passado e presente. Assim, o texto analisa o mercado de trabalho brasileiro contemporâneo com especial ênfase sobre os parâmetros precários de acesso para as mulheres negras.

Palavras-chave: escravidão; pós-emancipação; relações de raça e gênero; mercado de trabalho; discriminação.

Neste artigo procuramos refletir sobre aspectos do passado e do presente da mulher negra tanto na escravidão como num tempo presente da pós-emancipação, mais recente e não menos importante. ' Há silêncios na história de ontem e de hoje; sobre o papel das relações de gênero e raça no passado escravista - entre a imagem de mucamas e a suposta permissividade sexual - nas primeiras décadas da abolição com a estigmatização e a erotização do corpo da mulher negra; e no tempo presente em que indicadores sociais apontam desigualdades no mercado de trabalho e preponderância feminina na chefia dos domicílios das grandes regiões metropolitanas. Embora os estudos sobre gênero tenham

Copyright (c) 2008 by Revista Estudos Feministas.

1 Uma reflexão útil aparece em Célia Maria Marinho de AZEVEDO, 1988. 
ampliado horizontes ${ }^{2}$ e eixos teórico-metodológicos, ainda pouco conhecemos a respeito das conexões históricas entre raça e gênero. ${ }^{3}$ As reflexões sobre as experiências das mulheres negras nas comunidades escravas e nas primeiras décadas da pós-emancipação no Brasil continuam ausentes, salvo as exceções que destacaremos.

De início, um caminho necessário seria pensar as relações de gênero nas sociedades africanas pré-coloniais e suas dimensões (possíveis) reinventadas na diáspora. Para isso, teríamos que abandonar a retórica da vitimização de uma África romantizada no passado e no presente. Analisando os caminhos da literatura africanista, Patrick Manning destaca como as visões sobre uma África eterna foram revistas nas últimas décadas por estudos mais preocupados com as complexas transformações nas várias sociedades $\mathrm{e}$ microssociedades africanas, ${ }^{4}$ ou seja, as mudanças sociais e as dinâmicas próprias na África. Ocorreram impactos socioeconômicos e demográficos não somente provocados pelo comércio atlântico de escravos, uma das principais vias de contato entre africanos e europeus da metade do século XVI até o final do XX. Para as renovadas abordagens, entre as questões principais estavam - além da natureza das fontes e os sentidos das conclusões - as análises sobre a escravidão na própria áfrica, o impacto do comércio negreiro nas sociedades pré-coloniais assim como o conjunto de fatores demográficos (alteração de preços, quantidade, faixa etária, composição sexual). Refutando a dicotomia de sociedades robustas/resistentes à pressão ou aquelas frágeis e facilmente abaláveis, surgiram reflexões detalhadas sobre regiões, áreas, sociedades e microssociedades onde lógicas internas diversas - tais como secas, doenças e fome - causaram impactos devastadores; sem falar que em alguns casos ocorreram índices de recuperação e taxas de crescimento natural.

No presente artigo propomos um percurso próprio. Inicialmente abordamos os estudos históricos e as temáticas de gênero e do protagonismo negro. Avançamos na análise de algumas fontes que podem oferecer uma face do universo da mulher negra na sociedade escravista, suas expectativas, vivências e projetos. Na segunda parte, com base em dados agregados, propomos um salto histórico e mergulhamos nas lógicas do mercado de trabalho no Brasil de hoje e nos impactos sobre os perfis e as vidas das mulheres negras. Juntando retratos do passado e do presente, sugerimos reflexões sobre o papel da mulher negra na história e na sociedade brasileira.

\section{Escravidão, protagonismo da mulher negra e historiografia: caminhos e possibilidades}

Ao contrário do Caribe e dos EUA, ainda são poucos os estudos no Brasil que tratem das sociabilidades e do cotidiano de escravas, libertas, africanas e crioulas. Tanto nas sociedades africanas como na diáspora, mulheres eram conhecidas por sua força e poder espiritual. ${ }^{5}$ Elaboraram formas de enfrentamentos, contrariando a idéia de que aceitavam a dominação com passividade. Uma das bases de poder verifica-se na luta pela manutenção da família negra. Agiam na proteção da integridade física e psicológica de seus filhos e companheiros, assim como de toda a comunidade da qual faziam parte. ${ }^{6} \mathrm{Na}$

\footnotetext{
2 Ver: Maria Odila Leite da Silva DIAS, 1984; Magali ENGEL, 1989; Marta de Abreu ESTEVES, 1989; Sandra Lauderdale GRAHAM, 1988; e Rachel SOIHET, 1989.

${ }^{3}$ Ver Mary Del PRIORE, 1988, 1993.

${ }^{4}$ Patrick MANNING, 1988.

${ }^{5}$ Numa perspectiva africanista, Pantoja recupera as dimensões de poder e gênero-destacadamente Nzinga Mbandi - nas relações comerciais do tráfico em áreas centro-ocidentais no século XVII. Ver Selma PANTOJA, 2000.

${ }^{6}$ Mary ELLISON, maio 1983.
} 
tentativa de impedir que filhos e esposos fossem vendidos separadamente, recusavam-se a trabalhar e ameaçavam os senhores com o suicídio e o infanticídio. Fazendeiros temiam especialmnte envenenamentos que poderiam ser praticados por mucamas. Num mundo cercado de opressão, construíam ambientes de auto-estima e se tornavam decisivas, por exemplo, para possibilitar fugas ou obter informações a respeito de vendas e transferências indesejáveis. Providenciando suprimentos, muitas delas prestavam auxílio providencial aos escravos em fuga ou àqueles interessados em escapar. Ajudando a manter a integridade dos arranjos familiares, assim como a riqueza e a originalidade da cultura forjada em torno deles, elas foram os primeiros agentes da emancipação das comunidades afrodescendentes na diáspora. ${ }^{7}$

Estudos a respeito das experiências das mulheres escravas nas Américas têm apontado para o grau de resistência delas no interior das plantações. Não cooperadoras no trabalho diário tinham que ser castigadas severamente. ${ }^{8}$ Nas áreas rurais " onde a maior parte estava empregada nas plantações " era por meio da linguagem e da música que educavam seus filhos, reinventando sentidos culturais. Nas áreas urbanas, ocuparam importantes espaços, fazendo deles territórios dos mercados de trabalho, dos seus próprios corpos, desejos e identidades de gênero envolventes. A propósito, no século XVI, durante um embarque de escravos realizado por portugueses na África, um piloto de navegação anônimo comentou sobre a necessidade de se colocarem homens e mulheres separados nos porões dos navios negreiros. Segundo ele, as mulheres, quando viajavam junto aos homens, freqüentemente os instigavam a se revoltar contra a tripulação. ${ }^{9} \mathrm{~A}$ função das mulheres no interior das senzalas podia representar a reconstrução e a recriação permanente de aspectos culturais originais e, portanto, a edificação de sólidas comunidades. ${ }^{10}$ Uma das características fundamentais das culturas escravas em toda a América foi, sem dúvida, a manutenção da família nos seus variados sentidos." Sendo a espinha dorsal na constituição do parentesco, a mulher tinha o papel-chave na transmissão oral das crenças e dos valores de uma comunidade negra em gestação. ${ }^{12}$

No Brasil, os poucos estudos sobre a mulher escrava despontaram somente nos últimos 20 anos. Na década de 1980, Maria Odila realizou uma investigação pioneira lançando luz sobre as práticas sociais e a vida cotidiana de negras, escravas e libertas em São Paulo do século XIX. ${ }^{13}$ Outras abordagens surgiriam nos estudos de Sônia Giacomini e Maria Lúcia Mott. ${ }^{14}$ Também a obra clássica de Mary Karasch sobre escravidão urbana destacou a importância das mulheres africanas ocidentais no mercado de trabalho urbano. ${ }^{15}$ Já Luciano Figueiredo e Liana Reis analisaram para as Minas Gerais setencentistas a especificidade das negras de tabuleiro, provavelmente as precursoras da quitandeira típica do século XIX. ${ }^{16}$ Para Salvador, Cecília Soares abordaria o papel central das africanas no comércio urbano. ${ }^{17}$ Assim como as dimensões atlânticas sobre as quintadeiras

\footnotetext{
7 Silvia W. de GROOT, set. 1986; Bernard MOITT, 1996; e Michael MULLIN, maio 1985.

${ }^{8}$ Bárbara BUSH, 1985.

${ }^{9}$ A. C. de M. SAUNDERS, 1982.

${ }^{10}$ BUSH, 1985.

1 Mais recentemente a historiadora Isabel Reis tem trabalhado com o conceito de "família negra" na escravidão, ver Isabel Cristina Ferreira dos REIS, 1999.

12 Ver BUSH, 1990.

${ }^{13}$ Ver DIAS, 1985, 1995.

14 Sônia Maria GIACOMINI, 1988; e Maria Lúcia de Barros MOTT, 1988.

${ }^{15}$ Mary C. KARASCH, 2000. Ver ainda Margareth M. BAKOS, jul./dez. 1990.

16 Luciano R. A. FIGUEREDO, 1993, 1997, 1998; Luciano R. A. FIGUEREDO e Ana Maria Bandeira de Mello MAGALDI, 1985; e Liana Maria REIS, 1989.

17 Cecília Moreira SOARES, 1994, 1996.
} 
apareceram nos estudos de Selma Pantoja e Carlos Eugênio Líbano Sores, ${ }^{18}$ mais recentemente os estudos de Eduardo França, Júnia Furtado e Sheila Faria resgataram as conexões entre a conquista da liberdade - via alforria - e a força das relações de gênero no pequeno comércio para mulheres negras, forras e livres. ${ }^{19}$

Provavelmente outros importantes estudos - para além da nossa capacidade de atualização -poderiam ser citados. Embora estudos e autores apontados - não necessariamente poucos - tenham importância, insisto que precisamos conhecer mais das vivências das mulheres negras na escravidão e nas primeiras décadas da pós-emancipação. ${ }^{20}$ É possível - propomos nesta primeira parte do artigo - acompanhar trajetórias e personagens para entender o cotidiano das mulheres africanas e crioulas. ${ }^{21}$ Interessaria fundamentalmente localizar vozes femininas do passado, não apenas sons da opressão, do poder público, da medicina e das elites letradas. Entre os caminhos abertos mais recentemente, encontram-se as análises sobre as narrativas encontradas em testamentos de libertas, ex-escravas, africanas, crioulas e pardas. Ao deixarem legados e heranças, falaram das suas vidas, das experiências da escravidão, dos mundos do trabalho, das suas expectativas e mesmo afetividades, esperanças e recordações. Vejamos alguns testamentos para o Rio de Janeiro, nas regiões de Irajá, Inhaúma e Iguaçu, nos séculos XVIII e XIX.

O que falou a preta forra Sebastiana Ignácia antes de morrer?Aos 28 de setembro de 1826 foi sepultada numa "cova da Fábrica"; teve todos os sacramentos, sendo amortalhada em hábito de São Francisco e encomendada pelo pároco, incluindo um "dobre de sinos". Ficou "doente de cama de moléstias", dois dias antes - na presença do padre e do tabelião - fez seu testamento. Seguindo o ritual e a natureza dos testamentos da época, revelaria ser "natural do Gentio da Guiné" e casada em "face da Igreja com Felipe de Souza, preto forro", e "desse Matrimônio não tem filho algum, nem antes dele". Sendo "irmã de Nossa Senhora do Rosário de sua Freguesia de Inhaúma", contraíra dívidas com a irmandade e as deixava para o seu marido pagar. Mandava rezar missa e libertava dois escravos que possuía "as duas crias Maria, e Cândido, os deixa forros, e libertos como se de ventre livre nascidos fossem". Para a afilhada Maria, filha de Isidora Maria, legava "por esmola uma dobra" e para a "comadre Isidora deixa uma baeta de lemiste". Para os "mais seus afilhados deixa[va] a cada um quatro patacas". Quanto a "Maria crioula do Engenho Velho sua afilhada e de seu marido escrava de Dona Isabel deixa[va] uma dobra", e o mesmo valeria para "Emerenciana crioula sua afilhada [que] deixa[va] uma dobra, a qual é também escrava da mesma Dona Isabel". Eram todas escravas de Antônio José de Souza.

Caminho semelhante tomou a vontade de Rita Luiza Suzana, falecida em outubro de 1834. Uma africana de "nação Benguela", mas que no seu testamento afirmou ser "Católica Romana, natural da Costa de Leste, casada na forma da Lei com Pedro Antônio Álvares também da Costa de cujo Matrimônio não" tivera filhos. Sem herdeiros diretos " tal como Sebastiana acima ", deixava legado para afilhados, como duas doblas para Bernardo, filho de Bernardo João Gomes, preto já falecido, mas que o seu herdeiro e testamenteiro só daria quando ele tivesse "idade de se poder reger". Como testamenteiro, além do marido, havia também Domingos da Silva, outro preto forro. ${ }^{22}$

\footnotetext{
18 PANTOJA, 2001.

${ }^{19}$ Sheila de Castro FARIA, 2000; Júnia Ferreira FURTADO, 2001; e Eduardo França PAIVA, 2001.

${ }^{20}$ Ver a introdução de Olívia CUNHA e Flávio GOMES, 2007.

${ }^{21}$ Dois exemplos recentes de tentativas na área da pesquisa histórica de analisar personagens femininas negras aparecem em: FURTADO, 2006; e GRAHAM, 2005. Um importante repertório de perfis e biografias de mulheres negras do passado e do presente aparece em Schuma SCHMAHER e Érico Vital BRAZIL, 2007.

${ }^{22}$ Arquivo da Cúria Metropolitana do Rio de Janeiro, notação 0632, livro de testamentos e óbitos (Inhaúma), 18 set. 1826 , fl. 89 .
} 
Tudo muito igual apareceria no testamento de uma outra africana de Benguela, em 1848. Os anos se passaram, mas Joana Batista acompanhou o padrão das mulheres africanas e forras, moradoras na freguesia de Inhaúma. Mesmo "estando doente", revelaria ser "católica romana", viúva de Mateus José Mascarenhas, embora sem filhos. Novamente uma africana, casada, sem filhos e que deixava bens para parentes e afilhados. Seus testamenteiros eram Valentim Correia da Silva, "por estar em sua casa, e por virtude da caridade com que me tem tratado", e Gregório Pinheiro, para quem como herança deixava duas doblas. Ainda distribuiu esmolas para Ignácia Maria e as filhas da sua "parenta" Isabel Maria do Carmo, viúva do preto seu "parente", Manoel Caetano, e moradora no Engenho Novo. Cada uma receberia seis doblas logo depois do seu falecimento. Por serem crianças, o dinheiro seria "posto em mão segura para só lhes ser entregue quando tiverem uso da razão". Os outros bens de Joana eram "uma situação [lotes de terras] neste Distrito" que estava "alugada a Antônio Nunes por sete mil réis mensais, o qual me tem pago até o mês atrasado".

De fato, padrões de posse, desejos e expectativas diferentes tinham as mulheres negras que deixaram testamentos na freguesia da Piedade de Iguaçu, no século XVIII. Vejamos o que dissse Roza Maria da Silva. Falecida em 1782 e "sepultuda em cova da Irmandade do Rosário", tratava-se de uma preta forra viúva, nascida na Costa da Mina e batizada na freguesia de Nossa Senhora da Conceição de Antônio Dias, em Vila Rica, Minas Gerais. Ela possuía duas varas de cordão, uma imagem da Conceição, umas contas do pescoço e um par de brincos. Além disso, contava com um tacho de cobre, um forno de cobre e "uma roda de mandioca com seus pertences". Era igualmente proprietária de escravos, com "uma escrava de nação mina por nome Rita de idade que parece ser de quarenta e seis anos pouco mais ou menos [...] e os dois seguintes ambos filhos da dita escrava" e mais "um criolo por nome Manoel de vinte oito anos e outro pardo por nome Benedicto da Irmandade de vinte e dois anos". Quanto às dívidas, fez questão de registrar aquela de "duas patacas" a uma preta por nome Luiza, "da qual nem sei nem há noticias", mas que os seus "testamenteiros consultaram com quem melhor o entenda o que deles se há de fazer quando a dita não apareça". ${ }^{23}$ Registrou bens, dívidas, direitos e obrigações. Aos cativos Manoel e Benedicto deixava a

obrigação de cada um por si mandar dizer por minha alma mais capela de missas e outras tantas missas mandaram os ditos dizer pela alma de meu marido ficando ambos como obrigação de servir ao dito meu marido até o seu falecimento e depois dele tendo dado inteiro cumprimento a todas estas minhas disposições os deixo a ambos livres e forros e de mais Ihes deixo o forno de Cobre e roda com todos seus pertences para deles se servirem pertencendo a cada um parte iguais. ${ }^{24}$

A escrava Rita deveria "mandar dizer meia capella de missas e dará mais meia dobla pela metade que me pertence e o mais de seu valor toca a meu marido que disporá como Ihe parecer cuja meia dobla se dará a minha prima Elena Maria da Silva e quando já seja falecida se lhe dará ao mesmo em missas por sua alma". ${ }^{25}$ Ao restante dos bens recomendava do "que pertencer a minha metade se mandaram dizer doze missas de

\footnotetext{
${ }^{23}$ Estes testamentos se encontram no Livro de Óbitos da Freguesia de Nossa Senhora da Piedade de Iguaçu, 1777-1798, Arquivo da Cúria de Nova Iguaçu. Agradeço ao pesquisador e diretor do Arquivo, Antônio de Lacerda, a indicação desses testamentos.

${ }^{24}$ Livro de Óbitos da Freguesia de Nossa Senhora da Piedade de Iguaçu, 1777-1798, Arquivo da Cúria de Nova Iguaçu.

${ }^{25}$ Livro de Óbitos da Freguesia de Nossa Senhora da Piedade de Iguaçu, 1777-1798, Arquivo da Cúria de Nova Iguaçu.
} 
esmola de pataca pelas almas do purgatório e também no dia do meu falecimento de se daram a doze pobres esmola de dois vinténs a cada um". E por fim declarava: "não devo mais nada a pessoa alguma".

Domingas Cabral de Mello, preta forra viúva, falecida em 1778, garantiu ser "gentia de guiné e batizada na freguesia da cidade de Luanda" e contou mais um pouco da sua história ao revelar ter vindo da sua "terra para esta de idade de doze anos e nesta mesma terra" casara Sebastião Cabral, um preto Ganguela, já falecido. Ela teve três filhos, que já tinham falecido, restando apenas dois netos, que instituía como herdeiros. Apesar de moradora em Iguaçu, queria ser sepultada na cidade, especialmente na igreja de Santa Rita, com muitas missas celebradas. Possuía - nesta ordem - os escravos José Rebolo, Maria Benguela e "um filho da mesma, Luis", um forno de cobre de fazer farinha, uma roda de relar mandioca, uma prensa e "as cazas donde vivo e todas as mais benfeitorias que se achar no dito sítio onde" era moradora. Também Ihe pertenciam "mais dois pares de brincos de ouro um de diamantes". ${ }^{26}$ Sobre o "crioulinho por nome Luis" que ela "andava na deligencia de o forrar", instruía aos testamenteiros que se recebesse "o seu valor em minha vida lhe passarei a sua Carta de Liberdade e se eu morrer sem ter recebido o seu valor ficara cativo".

O que nos revelou Joana Gonçalves, uma preta forra, falecida em 1789? Era "natural e batizada em Ganguela", fora casada com João Ramos, um africano de "Nação Congo já falecido", mas sem filhos. Declarando ser irmã da Irmandade do Rosário, queria que seu corpo fosse "amortalhado no hábito de Santo Antonio". Quanto ao casal de escravos que possuía, determinou que João trabalharia mais cinco anos "para neste tempo dar cinco doblas para a sua alforria" e que Maria ficaria igualmente mais cinco anos, porém daria "quatro doblas para sua alforria".

A africana Gracia Maria, "natural de Gentio de Guiné" e viúva, ao morrer deixou dois escravos de nação Angola, uma casa de farinha com todos os seus pertences, um tacho velho, um caixão para farinha, duas caixas, quatro enchadas, dois machados, uma espingarda, um facão e "mandiocas e roças". Determinou que sua escrava Lucrecia, após sua morte, deveria permancer no seu "sitio trabalhando junta com o outro dito meu escravo para desfructarem o [que] estiver plantado de baixo do dominio de meu testamenteiro". A novidade no seu testamento foram as dívidas. Contraíra uma com Damião, escravo de Francisco Barboza, no valor de 22,400 réis, "dinheiros que tinha dado a guardar ao dito defunto meu marido, e se gastou com o dito digo sua molestia e enterro cuja, quantia meu Testamenteiro Ihe pagará sem contenda de justiça", e outra com Francisco, também escravo de Francisco Barboza, no valor de 14,080 réis, "dinheiro que tambem tinha dado a guardar ao dito defunto meu marido, e se gastou cujo dinheiro meu Testamenteiro Ihe pagará sem contenda de justiças". Da irmandade, no caso a Confraria de Nossa Senhora da Conceição, de que participara seu marido, era devedora de 26,430 réis, que também prometia pagar. Para a escrava Lucrécia devia também 4,000 réis, que deveria descontar das três doblas solicitada para a sua alforria. Devia também a Isabel de Almeida, preta forra, em função das "onze patacas dinheiro" por ela emprestado. Tinha dívidas, mas também credores. De José Rodrigues, um preto forro, morador na cidade do Rio de Janeiro, teria a receber 38,400 réis "por um credito que me passou de resto de valor de uma crioula minha escrava por nome Izabel que ele como seu pai natural pretende forrar". Em caso de não pagamento, determinou expressamente que não fosse passada carta de alforria, mas sim fosse vendida a escrava, "pois este foi o trato" feito com o forro José. Seu testamento não foi apenas de expectativas de recebimentos ou promessas de pagamento de dívidas. Alguns foram eleitos

${ }^{26}$ Para o papel da indumentária e dos adereços para as mulheres negras no século XVIII, ver: Sílvia ESCOREL, 2000; e Silvia Hunold LARA, 1997. 
para receber seus bens deixados. Para João Gomes da Conceição, preto forro "que foi meu escravo", deixou a "casa de farinha com todos os seus pertences", o testamenteiro só entregaria após um ano da sua morte, uma vez que devia ainda se "fazer as mandiocas". Quem também teve sorte e ia ficar bonita por receber uma "saia de Gala preta" foi Escolastica de Magalhães, preta forra, moradora na cidade do Rio de Janeiro.

Essas narrativas, entrecortadas, pedaços de vida e experiências da escravidão e da liberdade inventadas, apresentam mulheres negras que conheceram a escravidão, algumas talvez na própria África, e redefiniram-na na diáspora; mais que isso, inventaram escravidão e liberdade. Reorganizaram suas vidas e de seus familiares; legaram bens para filhos, parentes e maridos. Há indicações de bens que vão do dinheiro, passando por roupas e adereços, além de terras e instrumentos agrícolas para a produção de mandioca. Não encontramos tão-somente mulheres submissas ou expostas à opressão, como mucamas, violentadas sexualmente ou oprimidas pelas relações de gênero no interior das próprias senzalas. Podemos avançar mais. Nos desejos e nos projetos de mulheres negras, organizando recursos que elas produziram e desejam legar, verificamos o olhar delas para as solidariedades de gênero e também para o universo da escravidão, ainda presente, pois muitas possuíam cativos. Há muitas experiências históricas das mulheres na escravidão e no período imediatamente posterior à abolição, ${ }^{27}$ nas cidades e nas áreas rurais. Parte substantiva dos dados das estatísticas contemporâneas sobre trabalhadores, mulheres e negros se refere a outros pedaços (sem rosto) de personagens da segunda geração da abolição; são mulheres negras, netas das filhas das primeiras libertas do último quartel do século XIX.

\section{Uma pós-emancipação contemporânea: mulher negra e mercado de trabalho}

Ligar passado e presente numa radical linha direta - tão-somente cronológica ou evolutiva - é sempre perigoso. Perdemos não só as nuances e as possibilidades interpretativas, mas fundamentalmente as conexões entre personagens, escolhas, políticas públicas, movimentos sociais, papel dos intelectuais, literatura, ideologias etc. Nesta segunda parte do artigo propomos um contraponto analítico. Partimos de comentários sobre alguns dos principais indicadores do mercado de trabalho brasileiro desagregados pelos grupos de cor ou raça e sexo. A idéia é verificar os impactos dos modelos de sociedade e as formas de inserção formal considerando as relações de gênero, especialmente a mulher negra. ${ }^{28}$ O período de tempo da análise cobrirá o intervalo de 1995 a 2006 . A fonte dos dados será a Pesquisa Nacional por Amostra de Domicílios - PNAD, realizada pelo Instituto Brasileiro de Geografia e Estatística - IBGE, e as tabulações foram realizadas pela equipe do Laboratório de Análises Econômicas, Históricas, Sociais e Estatísticas das Relações Raciais - LAESER, vinculado à Universidade Federal do Rio de Janeiro - UFRJ, por meio de seu Fichário das Desigualdades Raciais. ${ }^{29} \mathrm{O}$ LAESER organiza o Relatório Anual das Desigualdades Raciais no Brasil. O objetivo da exposição e da análise dos indicadores que seguem é justamente uma análise mais detida sobre os indicadores do mercado de trabalho da população negra do sexo feminino. Assim, os dados mostrarão cabalmente o quanto o mercado do fator trabalho é uma esfera especialmente hostil para a presença das mulheres negras.

\footnotetext{
${ }^{27}$ Em termos teóricos, pensamos aqui nas propostas de James C. SCOT, 1990.

${ }^{28} \mathrm{Um}$ trabalho pioneiro é de Luiza Helena de BAIRROS, 1987.

${ }^{29}$ LAESER.
} 
De 1995 a 2006, a população economicamente ativa - PEA brasileira, descontando a população residente nas áreas rurais da região Norte, apresentou um saldo líquido de ingresso de 20,6 milhões de pessoas. Quando se consideram os grupos de cor ou raça, observa-se que, entre os brancos, esse saldo líquido foi de 7,7 milhões de pessoas, ao passo que, entre os pretos e pardos, 12,6 milhões de pessoas. Portanto, ao longo do período analisado, a presença das pessoas negras no mercado de trabalho apresentou maior dinamismo diante do que ocorreu entre as de cor ou raça branca.

Com relação à evolução em números absolutos, desagregada por sexo, as maiores responsáveis por aquele saldo foram as mulheres, que contribuíram com $56,4 \%$ do crescimento da PEA ocupada. As mulheres negras, sozinhas, levaram cerca de 6,4 milhões de pessoas a mais para o mercado de trabalho. Os homens negros responderam pelo incremento líquido de 6,3 milhões de pessoas. Entre homens e mulheres brancos, respectivamente, o acréscimo líquido de ingresso no mercado de trabalho, entre $1995 \mathrm{e}$ 2006, foi de, respectivamente, 2,6 e 5, 1 milhões de pessoas.

No mesmo período, entre os homens, a PEA negra, em números absolutos de trabalhadores, superou a branca. Assim, em 2006, o número total de ocupados e desocupados negros totalizava 25,7 milhões, ao passo que os brancos, 25,6 milhões de pessoas. No caso das mulheres, a PEA branca superava a PEA negra em 2,59 milhões de trabalhadoras.

De 1995 a 2006, as taxas de participação no mercado de trabalho das mulheres brancas e negras cresceram, respectivamente, 7,0 e 4,4 pontos percentuais. Já entre os homens brancos e negros, os idênticos indicadores declinaram, respectivamente, 1,4 e 2,2 pontos percentuais.

A PEA ocupada em todo o País, excetuando-se os residentes nas áreas rurais da região Norte, obteve saldo líquido de 20,6 milhões de pessoas, de 1995 a 2006. Quando desagregada por cor ou raça e sexo, as maiores evoluções proporcionais se deram entre as mulheres: $27,1 \%$ entre as brancas e $42,7 \%$ entre as negras. Já na PEA masculina, a evolução relativa do número de ocupados foi de $10,2 \%$ entre os homens brancos e de $30,0 \%$ entre os negros. No total, o número de ocupados cresceu proporcionalmente, no período descrito, em $17,1 \%$ entre os brancos e $34,9 \%$ entre os negros.

Na Tabela 1 observa-se que na PEA branca ocupada, em 2006, a maioria era assalariada, sendo $36,8 \%$ do total com carteira assinada, havendo ainda $15,5 \%$ de assalariados sem carteira e 7,7\% de funcionários estatais, entre outros. De 1995 a 2006 , nesse contingente, o peso relativo dos assalariados com carteira assinada cresceu 3,6 pontos percentuais, o dos assalariados sem carteira cresceu 1,7 ponto percentual e o do funcionário público ou militar permaneceu estável.

A segunda forma mais relevante em termos relativos de ocupação para a PEA ocupada branca era a de trabalhadores por conta própria. Em 2006, essa condição representava a situação de 19,8\% do total desse grupo, de importância proporcional menor do que em 1995 , com $21,4 \%$. O emprego doméstico respondia por $6,1 \%$ do total de brancos ocupados, em 2006, proporção estável desde 1995 (Tabela 1).

Em 2006, as modalidades ocupacionais do emprego não remunerado e do trabalho em atividades para o próprio consumo representavam relativamente $2,6 \%$ e 5,3\% do total de ocupados, ambas comparativamente menos importantes do que em 1995. Já a condição de empregador representava a situação de $5,6 \%$ dos ocupados brancos em 2006 (em 1995, 4,5\%) (Tabela 1).

Ainda na Tabela 1, quando se analisa o perfil da população masculina branca ocupada, percebe-se que, em 2006, as principais modalidades de posições ocupacionais eram: o emprego privado com carteira assinada junto ao funcionalismo público e militares 
$(45,7 \%)$, o emprego por conta própria $(23,4 \%)$, o emprego privado sem carteira $(17,2 \%)$, a condição de empregador $(6,9 \%)$ e as ocupações não remuneradas $(3,6 \%)$.

Já para a PEA branca ocupada do sexo feminino, as principais modalidades de posição na ocupação, no mesmo ano, eram: emprego assalariado com carteira e funcionalismo público e militares (42,9\%), emprego sem carteira assinada (13,5\%), emprego por conta própria $(13,3 \%)$, emprego doméstico $(12,9 \%)$ e ocupação não remunerada $(7,4 \%)$.

Tabela 1 - Distribuição da PEA residente ocupada segundo grupos de sexo e de cor ou raça branca de acordo com posição na ocupação, Brasil, 1995 e 2006 (em \%)

\begin{tabular}{|c|c|c|c|c|c|c|}
\hline \multirow[t]{2}{*}{ Trabalhadores Brancos } & \multicolumn{2}{|c|}{ Homem } & \multicolumn{2}{|c|}{ Mulher } & \multicolumn{2}{|c|}{ Total } \\
\hline & 1995 & 2006 & 1995 & 2006 & 1995 & 2006 \\
\hline Empregado privado & $373 \%$ & $398 \%$ & $27.4 \%$ & $330 \%$ & $332 \%$ & $368 \%$ \\
\hline Empregado privado & & & & & & \\
\hline sem carteira. & $16,5 \%$ & $17,2 \%$ & $10,0 \%$ & $13,5 \%$ & $13,8 \%$ & $15,5 \%$ \\
\hline $\begin{array}{l}\text { Empregado } \\
\text { público/estatutário/militar. }\end{array}$ & & & & & & \\
\hline $\begin{array}{l}\text { público/estatutário/militar. } \\
\text { Empregado }\end{array}$ & $5,6 \%$ & $5,9 \%$ & $10,7 \%$ & $9,9 \%$ & $7,7 \%$ & $7,7 \%$ \\
\hline $\begin{array}{l}\text { doméstico com carteira. } \\
\text { Empregado }\end{array}$ & $0,3 \%$ & $0,3 \%$ & $2,7 \%$ & $3,9 \%$ & $1,3 \%$ & $1,9 \%$ \\
\hline $\begin{array}{l}\text { doméstico sem carteira. } \\
\text { Conta própria }\end{array}$ & $0,4 \%$ & $0,4 \%$ & $11,0 \%$ & $9,0 \%$ & $4,7 \%$ & $4,2 \%$ \\
\hline $\operatorname{com} 3^{\circ}$ grau. & $1,3 \%$ & $1,9 \%$ & $1,3 \%$ & $0,0 \%$ & $1,3 \%$ & $2,0 \%$ \\
\hline $\begin{array}{l}\text { Conta própria } \\
\text { sem } 3^{\circ} \text { grau. }\end{array}$ & $23,8 \%$ & $21,5 \%$ & $14,7 \%$ & $13,3 \%$ & $20,1 \%$ & $17,8 \%$ \\
\hline Empregador & & & & & & \\
\hline $\begin{array}{l}\text { com até } 5 \text { empregados. } \\
\text { Empregador }\end{array}$ & $4,0 \%$ & $4,7 \%$ & $1,9 \%$ & $2,8 \%$ & $3,2 \%$ & $3,9 \%$ \\
\hline $\begin{array}{l}\text { com mais de } 5 \text { empregados. } \\
\text { Trabalhador na construção }\end{array}$ & $1,7 \%$ & $2,2 \%$ & $0,7 \%$ & $1,0 \%$ & $1,3 \%$ & $1,7 \%$ \\
\hline $\begin{array}{l}\text { para o próprio uso. } \\
\text { Trabalhador na produção }\end{array}$ & $0,0 \%$ & $0,1 \%$ & $0,0 \%$ & $0,0 \%$ & $0,0 \%$ & $0,1 \%$ \\
\hline para o próprio consumo. & $1,1 \%$ & $1,4 \%$ & $7,0 \%$ & $4,2 \%$ & $3,5 \%$ & $2,6 \%$ \\
\hline Não remunerado. & $6,6 \%$ & $3,6 \%$ & $12,6 \%$ & $7,4 \%$ & $9,1 \%$ & $5,3 \%$ \\
\hline
\end{tabular}

Fonte: IBGE, microdados PNAD. Tabulações LAESER: Fichário das Desigualdades Raciais. No ano de 1995, não está incluída a população residente nas áreas rurais da região Norte (exceto Tocantins).

A Tabela 2 mostra a evolução da distribuição da PEA negra por posição na ocupação em 1995 e 2006. Segundo os dados, em 2006, a principal forma era a condição assalariada com carteira assinada, com $28,5 \%$ do total de ocupados e aumento relativo de 4,6 pontos percentuais desde 1995. A segunda e a terceira formas mais importantes foram, respectivamente, o trabalho por conta própria, com $21,2 \%$, e o emprego assalariado sem carteira assinada, com $20,7 \%$. Neste caso, desde 1995, a importância relativa de ambas as modalidades teve mudanças opostas: a assalariada sem carteira cresceu ligeiramente 0,7 ponto percentual e a autônoma diminuiu 1,6 ponto percentual. 
Tabela 2 - Distribuição da PEA residente ocupada segundo grupos de sexo e de cor ou raça negra de acordo com posição na ocupação, Brasil, 1995 e 2006 (em \%)

\begin{tabular}{|c|c|c|c|c|c|c|}
\hline \multirow[t]{2}{*}{ Trabalhadores Pretos \& Pardos } & \multicolumn{2}{|c|}{ Homem } & \multicolumn{2}{|c|}{ Mulher } & \multicolumn{2}{|c|}{ Total } \\
\hline & 1995 & 2006 & 1995 & 2006 & 1995 & 2006 \\
\hline Empregado privado & & & & & & \\
\hline $\begin{array}{l}\text { com carteira assinada. } \\
\text { Empregado privado }\end{array}$ & $27,7 \%$ & $33,0 \%$ & $17,8 \%$ & $22,0 \%$ & $23,9 \%$ & $28,5 \%$ \\
\hline sem carteira. & $25,9 \%$ & $25,2 \%$ & $10,6 \%$ & $14,2 \%$ & $20,0 \%$ & $20,7 \%$ \\
\hline Empregado & & & & & & \\
\hline $\begin{array}{l}\text { público/estatutário/militar. } \\
\text { Empregado }\end{array}$ & $4,6 \%$ & $4,6 \%$ & $7,4 \%$ & $7,5 \%$ & $5,7 \%$ & $5,8 \%$ \\
\hline $\begin{array}{l}\text { doméstico com carteira. } \\
\text { Empregado }\end{array}$ & $0,3 \%$ & $0,4 \%$ & $3,8 \%$ & $5,2 \%$ & $1,7 \%$ & $2,3 \%$ \\
\hline $\begin{array}{l}\text { doméstico sem carteira. } \\
\text { Conta própria }\end{array}$ & $0,6 \%$ & $0,7 \%$ & $19,0 \%$ & $16,6 \%$ & $7,7 \%$ & $7,2 \%$ \\
\hline $\begin{array}{l}\operatorname{com} 3^{\circ} \text { grau. } \\
\text { Conta própria }\end{array}$ & $0,2 \%$ & $0,5 \%$ & $0,0 \%$ & $0,4 \%$ & $0,2 \%$ & $0,4 \%$ \\
\hline $\operatorname{sem} 3^{\circ} \mathrm{grau}$ & $26,0 \%$ & $24,2 \%$ & $16,8 \%$ & $15,9 \%$ & $22,4 \%$ & $20,8 \%$ \\
\hline $\begin{array}{l}\text { Empregador com } \\
\text { até cinco empregados. } \\
\text { Empregador com }\end{array}$ & $1,6 \%$ & $2,0 \%$ & $0,6 \%$ & $1,1 \%$ & $1,2 \%$ & $1,6 \%$ \\
\hline $\begin{array}{l}\text { mais de cinco empregados. } \\
\text { Trabalhador na construção }\end{array}$ & $0,4 \%$ & $0,5 \%$ & $0,0 \%$ & $0,3 \%$ & $0,3 \%$ & $0,4 \%$ \\
\hline $\begin{array}{l}\text { para o próprio uso. } \\
\text { Trabalhador na produção }\end{array}$ & $0,0 \%$ & $0,3 \%$ & $0,0 \%$ & $0,0 \%$ & $0,0 \%$ & $0,2 \%$ \\
\hline para o próprio consumo. & $1,9 \%$ & $2,5 \%$ & $10,1 \%$ & $8,1 \%$ & $5,1 \%$ & $4,8 \%$ \\
\hline
\end{tabular}

Fonte: IBGE, microdados PNAD. Tabulações LAESER: Fichário das Desigualdades Raciais. No ano de 1995, não está incluída a população residente nas áreas rurais da região Norte (exceto Tocantins).

A condição de funcionário público e militar correspondia, em 2006, à posição na ocupação de 5,8\% da PEA negra ocupada, estável proporcionalmente desde 1995. No mesmo ano, o emprego doméstico respondia relativamente por $9,5 \%$ desse contingente, também uma proporção estável desde 1995. O trabalho para o próprio consumo e a ocupação não remunerada tiveram suas importâncias reduzidas proporcionalmente entre os pretos e pardos ocupados. No primeiro caso, de $5,1 \%$ para $4,8 \%$, e no segundo, de $11,4 \%$ para $7,0 \%$. Já a condição de empregador, escassa entre pretos e pardos, correspondia a 1,5\% em 1995 e $2 \%$ em 2006.

Quando desagregada por sexo, a distribuição da PEA ocupada negra, em 2006, segundo a posição na ocupação, evidencia importantes desigualdades de gênero. Entre os homens, as mais importantes posições ocupacionais eram: empregados com carteira assinada com funcionários públicos e militares $(37,6 \%)$, trabalhadores por conta própria $(24,7 \%)$, empregado sem carteira $(25,2 \%)$ e ocupação não remunerada $(5,7 \%)$. Nesse contingente, o emprego doméstico respondia por 1,1\% da PEA ocupada e a condição de empregador, por $2,5 \%$. 
Já na PEA negra do sexo feminino, no mesmo ano, os pesos relativos eram: assalariadas com carteira em conjunto com funcionárias públicas e militares $(29,5 \%)$, emprego doméstico $(21,8 \%)$, trabalhadoras por conta própria $(16,3 \%)$, ocupação não remunerada $(8,7 \%)$ e atividades para o próprio consumo $(10,1 \%)$. A condição de empregadora correspondia à situação de 1,4\% da PEA preta e parda: $1,1 \%$ com até cinco empregados e 0,3\% com mais de cinco (Tabela 2).

Em resumo, essa longa descrição permite algumas comparações visando evidenciar as diferenças de cor ou raça e de sexo nas distintas formas de distribuição das posições na ocupação do mercado de trabalho. Para simplificar, serão comentados somente os indicadores das respectivas distribuições da PEA ocupada segundo posição na ocupação em 2006, tal como constam nas Tabelas 1 e 2.

$\sqrt{ }$ A condição assalariada com carteira assinada era mais comum entre os trabalhadores brancos $(36,8 \%)$ do que entre os negros $(28,5 \%)$, entre os homens brancos $(39,8 \%)$ do que entre os negros $(33 \%)$ e entre as brancas $(33 \%)$ do que entre as negras (22\%).

$\sqrt{ }$ O emprego assalariado sem carteira assinada era mais comum aos homens negros $(25,2 \%)$ do que aos brancos $(17,2 \%)$. Entre as mulheres, o percentual de negras era ligeiramente superior.

$\checkmark$ O emprego de funcionário público ou militar era pouco mais comum às mulheres brancas $(9,9 \%)$ do que às negras $(7,5 \%)$ e aos homens brancos $(5,9 \%)$ do que aos negros $(4,6 \%)$.

$\sqrt{ }$ O emprego doméstico ocupava mais mulheres do que homens e mais negras do que brancas. Assim, das negras, uma em cada cinco era doméstica $(21,8 \%)$. A probabilidade de se encontrar uma mulher branca era 8,9 pontos percentuais inferior do que a de uma negra.

$\sqrt{ }$ O trabalho por conta própria era relativamente comum tanto entre brancos $(19,8 \%)$ como entre negros $(21,2 \%)$, com a diferença de que esse trabalho com diploma de ensino superior, embora pouco freqüente, era cinco vezes mais provável entre os brancos (2\%) do que entre os negros $(0,4 \%)$.

$\sqrt{ }$ A condição de empregador era pouco comum em ambos os grupos de cor ou raça e sexo. Todavia, na PEA ocupada negra esse percentual era ainda menor: $2,5 \%$ entre os homens e $1,4 \%$ entre as mulheres. Com mais de cinco empregados, então, essas proporções caíam para $0,5 \%$ para os homens e $0,3 \%$ para as mulheres. Na PEA branca ocupada a condição de empregador era de 6,9\% entre os homens e de $3,8 \%$ entre as mulheres. Com mais de cinco empregados, respectivamente, $2,2 \%$ e $1 \%$.

$\sqrt{ }$ O trabalho para o consumo próprio era quase seis vezes mais comum para uma mulher negra $(8,1 \%)$ do que para um homem branco $(1,4 \%)$. Um homem negro tinha uma probabilidade de viver com atividades de subsistência $(2,5 \%)$ em uma proporção 1,78 vezes superior a um branco igualmente $(1,4 \%)$.

$\sqrt{ }$ A ocupação não remunerada era mais comum entre as mulheres do que entre os homens. No caso das negras, a probabilidade de se encontrarem nessa condição era de $8,7 \%$ e das brancas, de $7,4 \%$. Na PEA masculina, o percentual de não remunerados era de $5,7 \%$ entre os negros e de $3,6 \%$ entre os brancos.

A Tabela 3 mostra a composição relativa, por cor ou raça e sexo, nas distintas modalidades de posição na ocupação em 2006. Percebe-se que a PEA ocupada branca era predominante nas modalidades do emprego com carteira, do funcionalismo público e 
militares, dos trabalhadores por conta própria com ensino superior concluído e dos empregadores. Já a PEA negra tinha maioria nas modalidades do emprego sem carteira assinada, do emprego doméstico, do trabalho por conta própria sem ensino superior completo, de construção para benefício próprio, de produção para o próprio consumo e não remunerada.

De 1995 a 2006, em todo o País, ocorreu um incremento líquido de 3,6 milhões de pessoas no número total de pessoas desocupadas em busca de ocupação na semana de referência das respectivas pesquisas. A grande contribuição para esse saldo foi da população feminina, com $68,4 \%$ desse total. Com a desagregação por cor ou raça e sexo, os negros correspondiam a $60,4 \%$ daquele incremento, sendo $22,2 \%$ de homens e $40,2 \%$ de mulheres. A PEA branca desocupada, por sua vez, contribuiu com $38,3 \%$, divididos em $9,8 \%$ de homens e $28,5 \%$ de mulheres.

Tabela 3 - Composição da PEA residente ocupada segundo grupos de sexo e de cor ou raça preta \& parda de acordo com posição na ocupação, Brasil, 2006 (em \%)

\begin{tabular}{|c|c|c|c|c|c|}
\hline & \multicolumn{2}{|c|}{ Brancos } & \multicolumn{2}{|c|}{ Pretos \& Pardos } & \multirow[t]{2}{*}{ Total $(*)$} \\
\hline & Homem & Mulher & Homem & Mulher & \\
\hline $\begin{array}{l}\text { Empregado privado } \\
\text { com carteira assinada. }\end{array}$ & $34,3 \%$ & $22,8 \%$ & $28,9 \%$ & $13,3 \%$ & $99,2 \%$ \\
\hline $\begin{array}{l}\text { Empregado privado } \\
\text { sem carteira. }\end{array}$ & $26,7 \%$ & $16,9 \%$ & $40,0 \%$ & $15,5 \%$ & $99,2 \%$ \\
\hline $\begin{array}{l}\text { Empregado } \\
\text { público/estatutário/militar. } \\
\text { Empreagdo }\end{array}$ & $24,7 \%$ & $33,1 \%$ & $19,5 \%$ & $21,9 \%$ & $99,2 \%$ \\
\hline $\begin{array}{l}\text { doméstico com carteira. } \\
\text { Empregado }\end{array}$ & $4,3 \%$ & $41,6 \%$ & $5,5 \%$ & $48,3 \%$ & $99,5 \%$ \\
\hline $\begin{array}{l}\text { doméstico sem carteira. } \\
\text { Conta própria }\end{array}$ & $1,8 \%$ & $36,1 \%$ & $3,3 \%$ & $58,2 \%$ & $99,4 \%$ \\
\hline $\begin{array}{l}\text { com } 3^{\circ} \text { grau. } \\
\text { Conta própria }\end{array}$ & $43,8 \%$ & $36,9 \%$ & $10,9 \%$ & $6,1 \%$ & $97,8 \%$ \\
\hline $\begin{array}{l}\text { sem } 3^{\circ} \text { grau. } \\
\text { Empregador }\end{array}$ & $31,4 \%$ & $15,7 \%$ & $36,0 \%$ & $16,3 \%$ & $99,3 \%$ \\
\hline $\begin{array}{l}\text { com até } 5 \text { empregados. } \\
\text { Empregador }\end{array}$ & $47,3 \%$ & $22,5 \%$ & $20,8 \%$ & $7,4 \%$ & $98,0 \%$ \\
\hline $\begin{array}{l}\text { com mais de } 5 \text { empregados. } \\
\text { Trabalhador na construção }\end{array}$ & $58,8 \%$ & $22,1 \%$ & $12,6 \%$ & $3,9 \%$ & $97,4 \%$ \\
\hline $\begin{array}{l}\text { para o próprio uso. } \\
\text { Trabalhador na produção }\end{array}$ & $29,7 \%$ & $3,4 \%$ & $55,7 \%$ & $10,4 \%$ & $99,1 \%$ \\
\hline para o próprio consumo. & $10,5 \%$ & $25,7 \%$ & $19,8 \%$ & $43,4 \%$ & $99,4 \%$ \\
\hline Não remunerado. & $16,8 \%$ & $27,4 \%$ & $27,0 \%$ & $28,3 \%$ & $99,6 \%$ \\
\hline
\end{tabular}

Fonte: IBGE, microdados PNAD. Tabulações LAESER: Fichário das Desigualdades Raciais. No ano de 1995, não está incluída a população residente nas áreas rurais da região Norte (exceto Tocantins).

Em 2006, 54,7\% do total de desocupados eram negros, sendo $23,9 \%$ de homens e $30,8 \%$ de mulheres. Em 1995 , os negros correspondiam a $48,6 \%$ do total $(25,3 \%$ eram homens e 23,3\% eram mulheres). Logo, em 11 anos, o peso relativo de negros na população 
desocupada aumentou, merecendo aqui uma atenção especial ao ocorrido entre as mulheres desse grupo.

Entre 1995 e 2006, as taxas de desocupação da PEA negra cresceram em um ritmo proporcionalmente mais acentuado do que as da branca. Assim, no período, a taxa cresceu 0,8 ponto percentual entre os homens brancos, ao passo que, entre os negros, 1,5 ponto percentual. No contingente do sexo feminino, entre as brancas, a taxa cresceu 3,1 pontos percentuais. Já entre as negras, 4,5 pontos percentuais, ou seja, neste último caso, mais de cinco vezes superior ao que ocorreu entre os homens brancos. Finalmente, na comparação da média de ambos os grupos, a taxa de desocupação entre os brancos passou de $5,8 \%$ para $7,7 \%$ e a dos negros, de $6,2 \%$ para $8,7 \%$.

Em 2006, o rendimento médio mensal real do trabalho principal dos homens brancos em todo o País equivalia a R\$ 1.164,00. Esse valor, no mesmo ano, era $56,3 \%$ superior à mesma remuneração obtida pelas mulheres brancas ( $R \$ 744,71$ ), 98,5\% superior à auferida pelos homens pretos e pardos ( $R \$ 586,26$ ) e $200 \%$ à recebida pelas mulheres pretas e pardas ( $R \$ 388,18)$.

\section{Reflexões conclusivas}

O que o conjunto de indicadores analisados na seção anterior revela é que a inserção das mulheres negras no mercado de trabalho é nitidamente pior do que a dos demais contingentes. Essas são as evidências que se obtêm de indicadores como posição na ocupação ( $75 \%$ de trabalhadoras sem garantias legais, mais de $20 \%$ ocupadas como empregadas domésticas), desocupação (na qual as taxas das mulheres negras eram, em 2006, mais do que o dobro das taxas dos homens brancos, além de ter crescido mais que proporcionalmente dentro do lapso de tempo estudado do que os demais grupos), rendimento médio do trabalho principal, no qual as mulheres negras recebiam apenas um terço do rendimento médio dos homens brancos, além de cerca de medade do rendimento médio das mulheres brancas e $66 \%$ do rendimento médio dos homens negros. Por outro lado, parece notório que tal realidade antes reflete o conjunto de discriminações vividas por esse contingente no seio de nossa sociedade, no qual à variável cor ou raça se somam os óbices derivados do sexismo, gerando um resultante no qual o resultado final parece superar o mero somatório das partes. Como juntar as experiências históricas do passado com os dados que acabamos de comentar? Não é necessário nenhum esforço analítico ou sofisticação teórica. Passados e presentes das mulheres negras são atuais e verdadeiros. ${ }^{30}$ Entre a vitimização e a produção simbólica de heróis, há experiências complexas de luta, opressão, humilhação, superação, amor, dor, desejos, escolhas, alegrias e desafios. Constatar isso pode ser pouco; mais importante será conhecer e tornar visíveis - em alguns espaços do conhecimento e da decisão sobre as políticas públicas - o universo das mulheres negras e o seu protagonismo de ontem e de hoje. ${ }^{31}$

\section{Referências bibliográficas}

ARQUIVO da Cúria Metropolitana do Rio de Janeiro. Livro de testamentos e óbitos. Rio de Janeiro, 1777-1826.

AZEVEDO, Célia Maria Marinho de. "Batismo da liberdade: os abolicionistas e o destino do negro". Histórias, Questões e Debates, Curitiba: UFPR, v. 9, n. 16, p. 38-65, jan. 1988.

\footnotetext{
${ }^{30}$ Pensamos aqui nas contribições de Sueli CARNEIRO, 1995, 2004.

${ }^{31}$ São destacadamente importantes - para pensar em comparações temporais entre outras coisas, por exemplo - os estudos de Márcia LIMA, 1993, 1995.
} 
BAIRROS, Luiza Helena de. Pecados no paraíso racial: o negro na força de trabalho da Bahia, 1950-1980. 1987. Dissertação (Mestrado em História) “ Universidade Federal da Bahia, 1987.

BAKOS, Margareth M. "Sobre a mulher escrava no Rio Grande do Sul". Estudos IberoAmericanos, Porto Alegre: PUC/RS, v. XVI, n. 7, p. 47-55, jul./dez. 1990.

BUSH, Bárbara. "Towards Emancipation: Slave Women and Resistance to Coercitive Labour Regimes in the British West Indian Colonies, 1790-1838". In: RICHARDSON, David. Abolition and its Aftermath: The Historical Context, 1790-1916. Frank Cass: University of Hull, 1985. p. 29-31.

. Slave Women in Caribbean Society, 1650-1838. Londres: Indiana University, 1990.

CARNEIRO, Sueli. "Gênero, raça e ascensão". Revista Estudos Feministas, São Paulo, v. 3, p. 301-596, 1995.

"A mulher negra na sociedade brasileira " o papel do movimento feminista na luta anti-racista". In: MUNANGA, Kabengele (Org.). História do negro no Brasil. Brasília: Fundação Cultural Palmares, 2004. p. 1-21.

CUNHA, Olívia; GOMES, Flávio. (Orgs.). Quase-cidadão. Antropologias e histórias do pósemancipação. Rio de Janeiro: Fundação Getulio Vargas, 2007.

DIAS, Maria Odila Leite da Silva. Quotidiano e poder em São Paulo no século XIX. São Paulo: Brasiliense, 1984.

. "Nas fímbrias da escravidão urbana: negras de tabuleiro e de ganho". Estudos Econômicos, São Paulo, v. 15, número especial, p. 167-180, 1985.

. Quotidiano e poder em São Paulo no século XIX. 2. ed. São Paulo: Brasiliense, 1995.

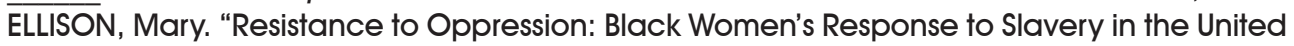
States". Slavery \& Abolition, Londres: Routledge, v. 4, n. 1, p. 56-63, maio 1983.

ENGEL, Magali. Meretrizes e doutores: saber médico e prostituição no Rio de Janeiro (18401890). São Paulo: Brasiliense, 1989.

ESCOREL, Sílvia. Vestir poder e poder vestir. O tecido social e a trama cultural nas imagens do traje negro (Rio de Janeiro - século XVIII). 2000. Dissertação (Mestrado) “ Instituto de Filosofia e Ciências Sociais, Universidade Federal do Rio de Janeiro, Rio de Janeiro, 2000.

ESTEVES, Marta de Abreu. Meninas perdidas: os populares e o cotidiano do amor no Rio de Janeiro da Belle Époque. Rio de Janeiro: Paz e Terra, 1989.

FARIA, Sheila de Castro. "Mulheres forras - riqueza e estigma social". Tempo, Niterói, v. 5, n. 9 , p. 65-92, jul. 2000.

FIGUEREDO, Luciano R. A.; MAGALDI, Ana Maria Bandeira de Mello. "Quitandas e quitutes; um estudo sobre rebeldia e transgressão femininas numa sociedade colonial”. Cadernos de Pesquisa, São Paulo, n. 54, p. 50-61, 1985.

FIGUEREDO, Luciano. O avesso da memória: cotidiano e trabalho da mulher nas Minas Gerais no século XVIII. Rio de Janeiro: José Olympio, EDUNB, 1993.

."Mulheres nas Minas Gerais". In: PRIORE, Mary Del (Org.). História das mulheres no Brasil. São Paulo: Contexto, UNESP, 1997. p. 141-188.

. Barrocas famílias: vida familiar em Minas Gerais no século XVIII. Rio de Janeiro: Hucitec, 1998.

FURTADO, Júnia Ferreira. "Pérolas negras. Mulheres livres de cor no Distrito Diamantino". In: . Diálogos oceânicos: Minas Gerais e as novas abordagens para uma história do Império ultramarino português. Belo Horizonte: UFMG, 2001. p. 81-126.

. Chica da Silva e o contratador dos diamantes: o outro lado do mito. 2. ed. São

Paulo: Companhia das Letras, 2006. 
GIACOMINI, Sônia Maria. Mulher e escrava; uma introdução ao estudo da mulher negra no Brasil. Petrópolis: Vozes, 1988.

GRAHAM, Sandra Lauderdale. Proteção e obediência: criadas e seus patrões no Rio de Janeiro (1860-1910). São Paulo: Cia. das Letras, 1988.

. Catarina diz não. Histórias de mulheres da sociedade escravista brasileira. São Paulo: Civilização Brasileira, 2005.

GROOT, Silvia W. de. "Maroon Women as Ancestors, Priests and Mediuns in Surinam". Slavery \& Abolition, Londres: Routledge, v. 7, p. 160-174, set. 1986.

KARASCH, Mary C. Vida dos escravos no Rio de Janeiro, 1808-1850. São Paulo: Cia. das Letras, 2000.

LAESER. Laboratório de Análises Econômicas, Históricas, Sociais e Estatísticas das Relações Raciais. Fichário das Desigualdades Raciais. Universidade Federal do Rio de Janeiro. Disponível em: www.laeser.ie.ufrj.br. Acesso em: set. 2008.

LARA, Silvia Hunold. "The Signs of Color: Women's Dress and Racial Relations in Salvador and Rio de Janeiro, ca. 1750-1815". Colonial Latin American Review, Londres: Routledge, v. 6, n. 2, p. 205-224, 1997.

LIMA, Márcia. "Raça, gênero e mercado de trabalho no Brasil". Estudos Afro-asiáticos, Rio de Janeiro, v. 23, 1993.

LIMA, Márcia. "Trajetória educacional e realização socioeconômica das mulherer negras". Revista Estudos Feministas, Rio de Janeiro, v. 3, n. 2, p.489-495, 1995.

MANNING, Patrick. "Escravidão e mudança social na África". Novos Estudos, São Paulo, n. 21, p. 8-29, 1988.

MOITT, Bernard. "Slave Women and Resistance in the French Caribbean". In: GASPAR, David B.; HINE, Darlene Clark. More than Chattel. Black Women and Slavery in the Américas. Bloomington: Indiana University Press, 1996.

MOT, Maria Lúcia de Barros. Submissão e resistência: a mulher na luta contra a escravidão. São Paulo: Contexto, 1988.

MULLIN, Michael. "Women and the Comparative Study of American Negro Slavery". Slavery \& Abolition, Londres: Routledge, v. 6, n. 1, p. 25-40, maio 1985.

PAIVA, Eduardo França. "Celebrando a alforria: amuletos e práticas culturais entre as mulheres negras e mestiças do Brasil". In: JANCSÓ, István; KANTOR, Iris (Orgs.). Festa: cultura \& sociabilidade na América portuguesa. São Paulo: Hucitec, Edusp/Fapesp, Imprensa Oficial, 2001. p. 505-520. v. 2.

PAIXÃO, Marcelo; CARVANO, Luiz (Orgs.). Relatório anual das desigualdades raciais no Brasil, 2007-2008. Rio de Janeiro: Garamont, 2008.

PANTOJA, Selma. Nzinga Mbandi. Mulher, guerra e escravidão. Brasília: Thesaurus, 2000.

. "A dimensão atlântica das quitandeiras". In: FURTADO, Júnia. Diálogos oceânicos:

Minas Gerais e as novas abordagens para uma história do Império ultramarino português. Belo Horizonte: UFMG, 2001. p. 45-67.

PRIORE, Mary Del. A mulher na história do Brasil. São Paulo: Contexto, 1988.

Ao sul do corpo: condição feminina, maternidades e mentalidades no Brasil Colônia. Brasília: EDUNB; Rio de Janeiro: José Olympio, 1993.

REIS, Isabel Cristina Ferreira dos. "Uma negra que fugio, e consta que já tem dous filhos: fuga e família entre escravos na Bahia Oitocentista". Afro-Ásia, Bahia: UFBA, v. 23, p. 2948, 1999.

REIS, Liana Maria. "Mulheres de ouro: as negras de tabuleiro nas Minas Gerais do século XVIII". Revista do Departamento de História, Niterói, n. 8, 1989.

SAUNDERS, A. C. de M. A Social History of Black Slaves and Freedom in Portugal, 1411-1555. Cambridge University Press, 1982. 
SCHUMAHER, Schuma; BRAZIL, Érico Vital. Mulheres negras do Brasil. Rio de Janeiro: Rede de Desenvolvimento Humano; São Paulo: Senac, 2007.

SCOT, James C. Domination and the Arts of Resistance. Hidden Transcripts. New Haven: Yale University Press, 1990.

SOARES, Cecília Moreira. Mulher negra na Bahia no século XIX. 1994. Dissertação (Mestrado em História) " Universidade Federal da Bahia, Salvador, 1994.

. "As ganhadeiras: mulher e resistência negra em Salvador no século XIX". Afro-Ásia, Bahia, n. 17, p. 57-72, 1996.

SOIHET, Rachel. Condição feminina e formas de violência: mulheres pobres e ordem urbana, 1890-1920. Rio de Janeiro: Forense Universitária, 1989.

[Recebido em novembro de 2008

e aceito para publicação em dezembro de 2008]

Revisiting the History of Differences and Inequalities: Notes about Gender, Slavery, Race and Pos-emancipation

Abstract: This article intends to reflect about general aspects of the slavery history, posemancipation and the present time of the Black woman, mainly in terms of her insertion in the labor market. At the first part the article deal with the bibliography about the slave woman and analysis some narratives about families, daily, and feminist strategies of slaves woman, creoles, emancipated and Africans into the XVIII and XIX centuries, in every cases based on will. On the second part, the article look for establish a dialogue between the past and the present time. So, the text analysis the contemporaneous Brazilian labor market with especial emphasis about the precarious parameters for the Black woman.

Key Word: Slavery; Pos-emancipation; Gender and Race Relations; Labor Market; Discrimination. 